\title{
Effects of Privacy Policy and Government Regulation on Trust of Consumers in Saudi Arabia: An Empirical Study
}

\author{
${ }^{1}$ Alharbi Nesreen Nasser A., ${ }^{2}$ Yanhui Li \\ 1,2 School of Information Management, Central China Normal University, Wuhan, China
}

\begin{abstract}
The research aimed to analyze the influence of privacy policy and government regulation on privacy risk concerns and trust. In other words, this paper attempted to highlight the importance of privacy policy and government regulations, which are two important aspects related to user's privacy rights. Data were collected through an online questionnaire to test the relationships between each FTC category in online privacy statements of websites/Government regulation and its effect on trust/privacy concerns and relationships. Two hundred sixty-eight respondents participated in the online survey. Results of the study indicate that the privacy policy has a positive impact on trust, whereas privacy risk concerns have a negative impact on trust. A clear and transparent privacy policy helps organizations to establish good relationships with consumers. Additionally, the privacy policy has a negative impact on privacy risk concerns. A strong and powerful privacy policy will significantly improve users' conservative attitudes about information sharing and privacy disclosure risks. Finally, government regulation has a positive impact on trust and a negative impact on privacy risk concerns. Government regulations such as disclosure, sharing, and use of personal information must be enforced to increase the willingness to use users' information, thereby enhancing users' trust in the relevant privacy policy protection laws. Clear and effective laws and regulations reduce users' fear of privacy policy; that is, the quality of the law will effectively motivate users to provide personal information. The findings of the research imply that there is a high level of concern among the citizens linked to their privacy risk, indicating people do not trust e-government sufficiently. Taking into consideration weak spots related to e-government policies a cybersecurity plan should be implemented. Besides that, consumers' trust related to privacy policy should be increased. This can be done by improving the standards for a privacy policy.
\end{abstract}

Keywords: Privacy policy, Privacy risk, Government regulation, Citizen's participation, Consumers in Saudi Arabia

\section{Introduction}

Citizen's participation, transparency, and cooperation represent the main elements of a democratic government. Modernization of government is vital to ensuring citizens access to information. Access to information is also critical for ensuring transparency in the government's activity and its democracy. Saudi Arabia is gradually planning to move towards information society. Thus, the Ministry of Communication and Information Technology organized the eGovernment program in close cooperation with the Ministry of Finance and Communication and Information Technology department. The main objective of the commission is to increase the productivity and efficiency of the public sector to improve the level of services provided for individual and business entities. 


\section{Alharbi Nesreen Nasser A., Yanhui Li \\ Effects of Privacy Policy and Government Regulation on Trust of Consumers in Saudi Arabia: An Empirical Study}

Moreover, objectives include increasing the return rate of investment and providing the accurate and necessary information in a short period. E-Government is considered as a unique business model, and its main objective is to create a global information network and provide government services to interested parties. Moreover, it focuses on the coverage of services for interested parties at any time and any place. The level of security provided by the EGovernment platform is critical for establishing the right balance between the society who takes advantage of new technology and consumers who are sure about their safety and privacy. Furthermore, e-government also enables the process of establishing IT legal systems that ensure the legal use of computers and information networks.

As modern digital technology has drastically affected the identity and value of information, it became easy to acquire personal data. With the emergence of the Internet, it became possible to crack security barriers protecting information. From another point of view, some of the sensitive personal data should be strongly protected by security regulations, and this includes users being able to grant permission to collect and process this information.

\section{Model Construction and Hypothesis Development}

\subsection{Research Model Construction}

According to the Saudi Arabia Vision 2030, the government aims to establish universal access to the first five levels of E-Government by 2030. Precisely, it is expected that this number reaches 25 by 2020 and 40 by 2025 . In this regard, the project provides an opportunity for citizens to perform many activities online, such as employment, job search, payment, and issuing of business records.

The activation of e-government services does not depend only on the technical aspects such as hardware, networks, software, and trained personnel, but it is related to many societal aspects. In our research of e-government services, there were no non-technical obstades, indicating that the creation of a societal reality for the acceptance of e-government services is superior to and precedes technical issues.

The law regulates data access and availability, confidentiality, depositing and archiving standards, declining of information, and the penalty for the intentional provision of false information. State institutions are to follow proscribed procedures regarding the deposition of official documents after the completion of the work, to protect and secure it from loss or damage, by all modern means and tools. Several different international legislations have been issued to protect the rights of individuals regarding privacy, addressing how different types of personal data were collected, stored, and saved. State and private institutions a lso play a critical role in securing data collected since there are a lot of cases related to violation of privacy rules, which resulted in the loss of valuable data.

It is critical to define the meaning of privacy. From the point of information system perspective, privacy is defined as the capability of the person to control different terms under which personal information is obtained and treated. Data collection, its secondary use, ownership of data, and its accuracy, as well as access, are considered essential characteristics related to privacy. Culnan, 1993; Loch \& Conger, 1996; Smith, 2004) Utilizing the data for purposes other than those for which they were collected for is regarded as a secondary use of data. There are four sub-categories concerning information privacy, i.e., the collection, error, unauthorized use, and improper access(Smith et al., 1996; Junglas, Johnson, and Spitzmueller, 2008).

There are two main ways under which excessive use of personal information can damage the consumer's privacy. Firstly, due to the lack of necessary privacy controls, sensitive and private 
information can be damaged. This can be seen in terms of unsolicited e-mails, credit card fraud, and identity theft. Moreover, the second problem arises when personal information is used for other purposes without the users' consent (Culnan 1993).

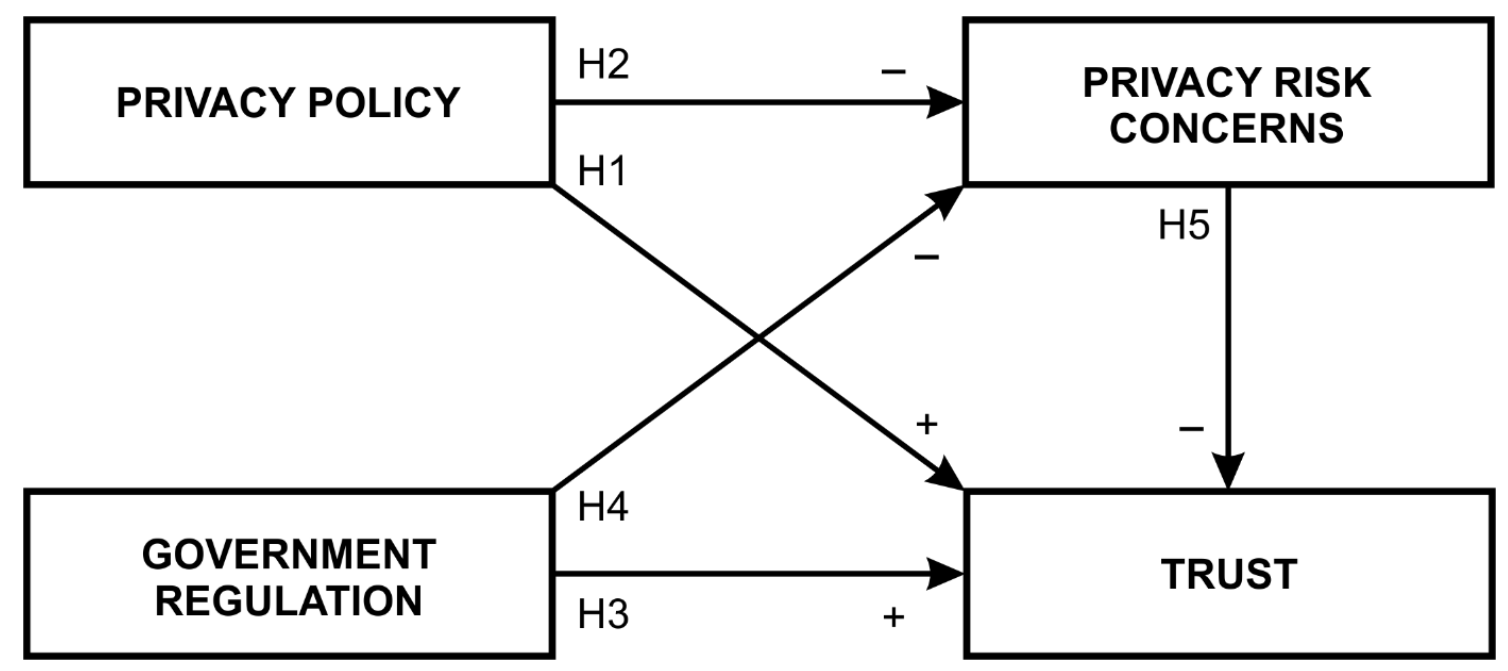

Figure 1: Research model, comprising of hypotheses with regards to concerns and obstacles in the use of e-Government services.

\subsection{Hypothesis Development}

Warren and Brandeis (1890) were the first scholars who defined privacy. Since then, the concept of privacy these scholars developed plays a critical role in terms of making personal, regulative, and political decisions. The idea of privacy was also used in regards to privacy at home and office, which involve the capability of making decisions without interference from the government (2007).

Moreover, it is also essential to mention some other definition of privacy comprising of some form of control over the potential secondary use of someone's personal information (Belanger, 2002) Privacy policy is formulated based on the standards of US federal trade commission principles. These principles include notice, choice, access, security, and enforcement. Before collecting any information and user's personal details, business entities should give "notice" about how they are going to collect and treat the collected information. This refers to the principle of "notice." The principle of choice indicates the choice regarding the treatme nt of personal information. In other words, users can choose how businesses can treat the collected data. Another critical principle is access. Access implies users have an option to view their personal information, how it was collected, and check their accuracy. The principle of security means that the collected data should be secure and accurate. Data integrity is also crucial since any amount of unnecessary data should be deleted, and some amount of data should be transformed into an anonymous form. Enforcement refers to the existence of an enforcement mechanism or instrument. All these principles are formulated based on national and international reports related to the practice of personal information privacy policy. These guidelines and procedures are essential to users as they provide useful information concerning the provision of personal information and the use of the website.

The relationship between the user and e-government platform service is grounded on customers' trust. The Privacy-Trust-Behavioral Intention model explains how privacy is essential in formulating users' trust and how users become more willing to use the website. In other words, trust impacts the user's behavior intention to use the site. Some researchers found that clear and credible Privacy Policy plays a critical role in building consumer trust 


\section{Alharbi Nesreen Nasser A., Yanhui Li \\ Effects of Privacy Policy and Government Regulation on Trust of Consumers in Saudi Arabia: An Empirical Study}

(Schoenbachler \& Gordon, 2002). A transparent privacy policy is essential in helping organizations to maintain a good customer relationship (Schoenbachler and Gordon, 2002).

Following this, we concluded:

\section{H1: privacy policy has a positive impact on trust.}

The use of computers and the Internet has diminished privacy protection and therefore increased the privacy risk, especially on the sites where it was possible to access information relatively easily and quickly. Concerns associated with privacy and its risks have long assumed a central role in the majority of privacy-related studies. Protecting human rights is the priority of a genuinely democratic country. In this regard, OECD introduced some guidelines, allowing the government to harmonize national laws with human rights. In this case, the legal system acts as a compelling feature to establish the control to enforce the criminal law, therefore imposing penalties for the breach of regulations and disobedience of rules.

The results of public surveys show that many respondents are afraid of losing track of how their personal information is going to be treated. In other words, it indicates that users have a high privacy concern. In this regard, Privacy Policy can be useful to reduce privacy concems, but only if users pay attention to the important contents of Privacy Policy. If the information provided is not understandable, users are less likely to read it thoroughly. On the other hand, if the Privacy Policy provides a clear and consistent message, users are more likely to give it serious consideration. The results of the study conducted by Milne and Culnan (2004) found a positive correlation between the online privacy policy and consumer trust.

Following this, we conclude:

H2: privacy policy has a negative impact on privacy risk concerns.

Xu et al. (2010) stated that judicial and legislative branches of government regulation are important factors impacting the protection of personal information. Government regulation should be drafted to ensure the security of users' personal information by requiring any entities to obtain user consent prior to collecting, using, or sharing this information. The main focus is to obtain consent from users before using their information.

Promoting confidence in the application of information technology in the digital environment and the protection of individuals' privacy are two fundamental objectives of legislation related to the privacy of personal information. According to this law, after meeting all the necessary points and requirements, the electronic document is more likely to be treated as the form of a paper document. In this regard, the electronic record will have the same legal power in terms of legal consequences and acts.

The law stipulates IT crimes and proscribed penalties and punishments for these types of crimes. Precisely, according to the law, a person committing any of the IT crimes can be either fined or jailed. Illegal access to electronic record sites to change the relevant information such as email, address, deleting, or adding any info is regarded as a crime. Computer Emergency Response Team is an organization playing an important role in increasing awareness and promoting knowledge of IT security at a national level. Following this, we concluded:

\section{H3: Government regulation has a positive impact on trust.}

Government regulation allows users to establish proxy control to protect their personal information. According to Spiro and Houghteling (1981) legal system is one of the most critical tools providing a proxy for the protection of personal information, and those not complying with the legal system will certainly receive punishment. The legislation allows third-party companies to collect personal information, but in this regard, it provides necessary means for how collected information should be treated and used. This prevents the breaches related to 


\section{Alharbi Nesreen Nasser A., Yanhui Li \\ Effects of Privacy Policy and Government Regulation on Trust of Consumers in Saudi Arabia: An Empirical Study}

the misuse and violations of contract. Moreover, enforcing authorities can help to familiarize users with their rights, so that they can know when their rights are violated. Therefore, not only government agencies but also individuals can claim their rights and report the violation. The existence of government regulation related to the protection of private information policy is crucial since it will help to reduce the privacy risk.

Following this, we concluded:

\section{H4: Government regulation has a negative impact on privacy risk concerns.}

The concept of privacy is defined as a users' claim regarding when, how, and to what extent their information is communicated to others. Previously conducted researches paid substantial attention to the privacy concerns from the perspective of direct marketing, electronic commerce, and online healthcare (Smith et al., 1996; Anderson and Agarwal 2011; Malhotra et al. 2004). The privacy concerns expressed by the respondents made them more cautious when providing their personal information. For example, Son and Kim (2008) mentioned that internet users who are more cautious about their personal data were more careful while providing their private information to websites they use. The majority of studies conducted in the field of Information Security have conceptualized privacy concerns as a user's ongoing worries about the possible loss of sensitive information (Malhotra, Kim, and Agarwal, 2004; Smith, Milberg, and Burke, 1996). Privacy concern is framed into a situation-specific context; thus, users might be worried when their personal information is exposed to the public or any other specific website. Mickingt and Chervany (2002) consider trust to be the precedent of information sharing, which can reduce the privacy concern.

Following this, we concluded:

$\mathrm{H} 5$ : privacy risk concern has a negative impact on trust.

\section{Data Sampling and Demographic Characteristics}

\subsection{Data Sampling}

(1) Research Method

Data were collected through an online questionnaire to test our theoretical model and to identify the relationships between each FTC category in online privacy statements of websites/Government regulation and its effect on trust/privacy concerns and relationships. The questionnaire was distributed to participants willing to provide personal information and benefit from disclosure. This study was designed to test 10 research hypotheses in two models, each of the models comprising of 5 hypotheses.

The questionnaire was translated into the Arabic language and posted to online social media apps, such as WhatsApp, Twitter, Snapchat, Facebook, and Instagram. Two hundred sixtyeight respondents participated in the survey. Variables used in the study are trust, privacy risk concerns, willingness to provide information, the benefit to disclose, the five FTC principles (notice, choice, access, security, enforcement), and Government regulation.

The research uses 5-Point Likert-type scales with anchors ranging from 1 - strongly disagree to 5-strongly agree for all variables, additional to demographic information.

\section{(2) Data Collection}

The sample consists of voluntary online respondents from Saudi Arabia, age 16 years old and over. To qualify for filling the questionnaire, the participants had to be using E-government in Saudi Arabia. The demographic contains the information for 268 respondents regarding gender, age, education, and use of e-govt. Services are provided in this section; the frequency tables and graphs are presented below. 
Alharbi Nesreen Nasser A., Yanhui Li

Effects of Privacy Policy and Government Regulation on Trust of Consumers in Saudi Arabia: An Empirical Study

\subsection{Demographic Characteristics}

The table below shows the portion of male and female respondents in the current study. Out of a total of 268 respondents, 130 were male, and 138 were female respondents, comprising $48.5 \%$ male respondents and $51.5 \%$ female respondents, respectively. The below figures are depicted in the pie chart below.

Table 1: Gender

\begin{tabular}{cccccc}
\hline & & & & Cumulative \\
& & Frequency & Percent & Valid Percent & \begin{tabular}{c} 
Percent \\
\hline Valid
\end{tabular} \\
& Male & 130 & 48.5 & 48.5 & 48.5 \\
& Female & 138 & 51.5 & 51.5 & 100.0 \\
& Total & 268 & 100.0 & 100.0 & \\
\hline
\end{tabular}

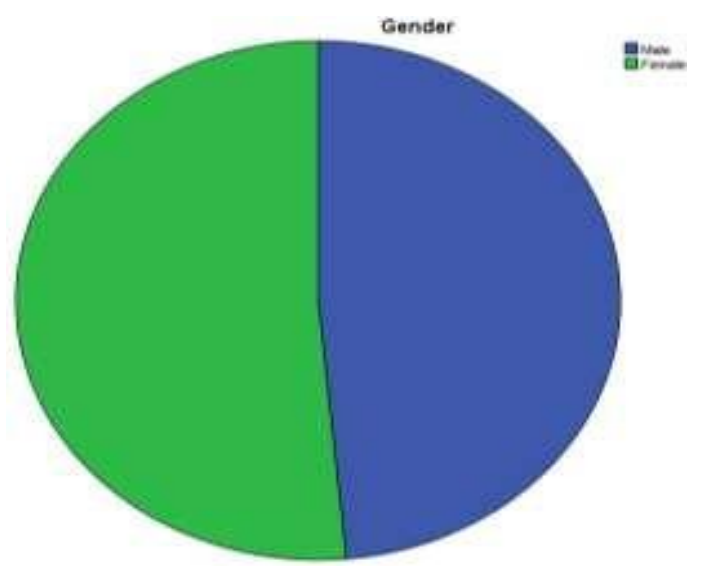

Figure 2: Gender

Table 2: Age

\begin{tabular}{cccccc}
\hline & & Frequency & Percent & Valid Percent & $\begin{array}{c}\text { Cumulative } \\
\text { Percent }\end{array}$ \\
\hline Valid & 16 to 24 & 26 & 9.7 & 9.7 & 9.7 \\
& 25 to 34 & 108 & 40.3 & 40.3 & 50.0 \\
35 to 44 & 89 & 33.2 & 33.2 & 83.2 \\
& 45 and & 45 & 16.8 & 16.8 & 100.0 \\
above & & & & \\
Total & 268 & 100.0 & 100.0 & \\
\hline
\end{tabular}

The age of the respondents is shown in the above table. The frequency distribution shows that the respondents between the age of 16 and 24 amounted to $10 \%, 25$ and 34 amounted to $40 \%, 35$ and 44 were around $33 \%$ while the respondent's age 45 and above were about $17 \%$. The above table is showing the frequency of $26,108,89$, and 45 for each age group, respectively. The pie chart below also depicts the distribution of the respondents concerning age in the graphical form. 
Alharbi Nesreen Nasser A., Yanhui Li

Effects of Privacy Policy and Government Regulation on Trust of Consumers in Saudi Arabia: An Empirical Study

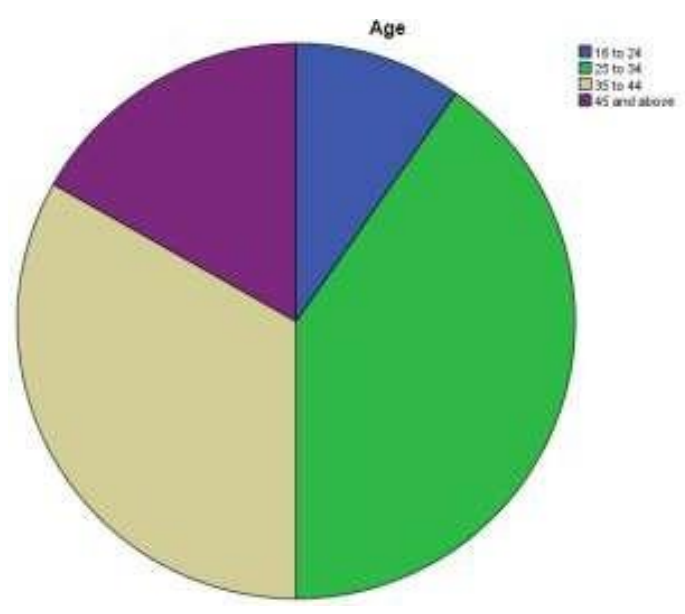

Figure 3: Age

Table 3: Education

\begin{tabular}{cccccc}
\hline & Frequency & Percent & Valid Percent & $\begin{array}{c}\text { Cumulative } \\
\text { Percent }\end{array}$ \\
\hline Valid & Secondar & 38 & 14.2 & 14.2 & 14.2 \\
& $y$ & & & & \\
& Bachelors & 167 & 62.3 & 62.3 & 76.5 \\
& Masters & 40 & 14.9 & 14.9 & 91.4 \\
& PhD & 23 & 8.6 & 8.6 & 100.0 \\
& Total & 268 & 100.0 & 100. & \\
& & & 0 & \\
\hline
\end{tabular}

The age of the respondents is shown in the above table. The frequency distribution shows that the respondents between the age of 16 and 24 amounted to $10 \%, 25$ and 34 amounted to $40 \%, 35$ and 44 were around $33 \%$ while the respondent's age 45 and above were about $17 \%$. The above table is showing the frequency of $26,108,89$, and 45 for each age group, respectively. The pie chart below also depicts the distribution of the respondents concerning age in the graphical form. As far as the education of the respondents is concerned, the respondents having secondary education were around $14 \%$, respondents having bachelor's degrees were approximately $62 \%$, Master's degree holders were about $15 \%$ while respondents having a Ph.D. were around 9\%. The frequency is also shown in the form of a graph in the pie chart below.

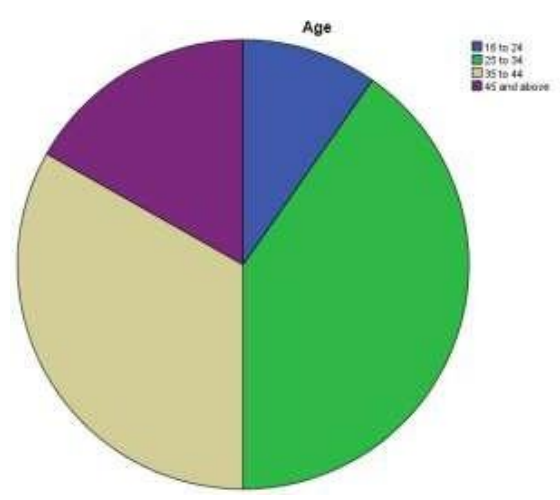

Figure 4: Education 
Alharbi Nesreen Nasser A., Yanhui Li

Effects of Privacy Policy and Government Regulation on Trust of Consumers in Saudi Arabia: An Empirical Study

Table 4: Use E-government

\begin{tabular}{cccccc}
\hline & & & & Cumulativ \\
& & Frequency & Percent & Valid & e \\
Valid & Once a Day & 54 & 20.1 & 20.1 & 20.1 \\
& Once a Week & 61 & 22.8 & 22.8 & 42.9 \\
& More than Once a Week & 55 & 20.5 & 20.5 & 63.4 \\
& Once a Month & 98 & 36.6 & 36.6 & 100.0 \\
Total & 268 & 100.0 & 100.0 & \\
\hline
\end{tabular}

The above table shows how frequently do the respondents use the e-govt. system. There are around $20 \%$ of respondents who use e-govt. once a day, approximately $23 \%$ use e-govt. once in a week, $21 \%$ use e-govt. more than once in a week while around $37 \%$ use e-govt. once in a month. The same distribution is depicted by the pie chart below.

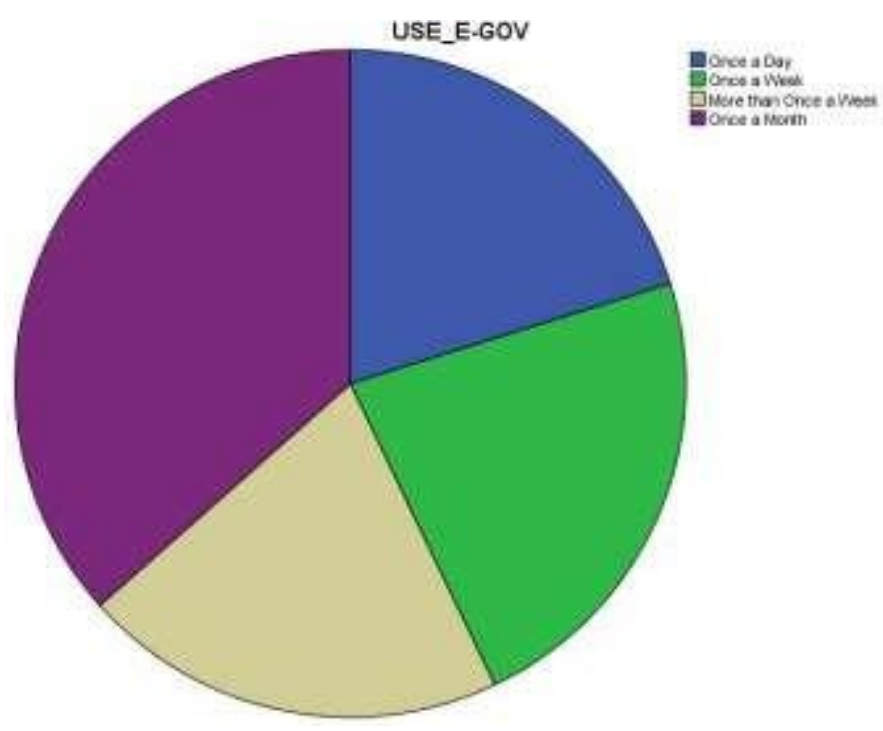

Figure 5: Use E-government

The demographic analysis section presented the frequency distribution along with the pie charts for 268 respondents. The demographic information contained age, education, gender, and frequency of using e-govt. by the respondents. The next section presents the preliminary analysis or data screening, such as missing value, outliers, and normality of the data.

\section{Data Analysis}

\subsection{Data Preparation and Screening}

It is vital to prepare the data prior to conducting the primary data analysis. This stage includes finding the missing values and outliers and testing for normality by applying skewness and kurtosis statistics.

\subsubsection{Missing Data}

The current data set did not have any missing values, indicating that in the data set, there was no missing data. This can be seen in the table provided below. 
Alharbi Nesreen Nasser A., Yanhui Li

Effects of Privacy Policy and Government Regulation on Trust of Consumers in Saudi Arabia: An Empirical Study

Table 5: Variables/Item valid and missing observations

\begin{tabular}{ccc}
\hline Variable/item & Valid N & Missing N \\
\hline Gender & 268 & 0 \\
Age & 268 & 0 \\
Education & 268 & 0 \\
Use of E-Government & 268 & 0 \\
TR1 & 268 & 0 \\
TR2 & 268 & 0 \\
TR3 & 268 & 0 \\
TR4 & 268 & 0 \\
TR5 & 268 & 0 \\
GR1 & 268 & 0 \\
GR2 & 268 & 0 \\
GR3 & 268 & 0 \\
GR4 & 268 & 0 \\
GR5 & 268 & 0 \\
PPI1 & 268 & 0 \\
PPI2 & 268 & 0 \\
PP1 & 268 & 0 \\
PP2 & 268 & 0 \\
PP3 & 268 & 0 \\
PP4 & 268 & 0 \\
PP5 & 268 & 0 \\
PP6 & 268 & 0 \\
PP7 & 268 & 0 \\
\hline & & \\
\hline
\end{tabular}

\subsubsection{Outliers}

Outlier detection is essential in quantitative data analysis. As the existence of outliers in a particular data set can potentially affect the analysis, and the findings of the studies can severely be affected. For finding the outliers $(z)$ score of the data is calculated and the $z$-score beyond the range of \pm 5 is said to be the outlier (Hair et al., 1998). The standardized $z$-scores are presented in the table below for each item the research questionnaire contained. None of the values exceed the mentioned range of absolute 5 , which is the indication of no issue of outliers in the data.

Table 6: Z-Scores to detect outliers

\begin{tabular}{llcc}
\hline & $\mathrm{N}$ & Minimum & Maximum \\
\hline Zscore(TR1) & 268 & -3.09409 & .72278 \\
Zscore(TR2) & 268 & -3.34519 & .66156 \\
Zscore(TR3) & 268 & -3.33570 & .68665 \\
Zscore(TR4) & 268 & -3.44029 & .71285 \\
Zscore(TR5) & 268 & -2.41182 & .98565 \\
Zscore(GR1) & 268 & -2.70967 & .98596 \\
Zscore(GR2) & 268 & -2.93619 & .87446 \\
Zscore(GR3) & 268 & -2.96033 & .90505 \\
Zscore(GR4) & 268 & -3.14175 & .80199 \\
Zscore(GR5) & 268 & -2.82231 & .81850
\end{tabular}


Alharbi Nesreen Nasser A., Yanhui Li

Effects of Privacy Policy and Government Regulation on Trust of Consumers in Saudi Arabia: An Empirical Study

\begin{tabular}{|c|c|c|c|}
\hline Zscore(PPI1) & 268 & -3.42869 & .76715 \\
\hline Zscore(PPI2) & 268 & -3.17731 & .78785 \\
\hline Zscore(PP1) & 268 & -1.61309 & 1.25939 \\
\hline Zscore(PP2) & 268 & -2.45878 & 1.00484 \\
\hline Zscore(PP3) & 268 & -2.46571 & 1.00767 \\
\hline Zscore(PP4) & 268 & -1.87643 & 1.00130 \\
\hline Zscore(PP5) & 268 & -2.20348 & .84443 \\
\hline Zscore(PP6) & 268 & -3.37282 & .75937 \\
\hline Zscore(PP7) & 268 & -3.44130 & .78444 \\
\hline Zscore(PP8) & 268 & -2.34962 & .93006 \\
\hline Zscore(PP9) & 268 & -2.87680 & .91181 \\
\hline Zscore(PP10) & 268 & -2.82341 & .77124 \\
\hline Zscore(PP11) & 268 & -3.16486 & .81255 \\
\hline Zscore(PP12) & 268 & -2.84382 & .74274 \\
\hline Zscore(PP13) & 268 & -2.97186 & .77618 \\
\hline Zscore(BTD1) & 268 & -2.92655 & .74276 \\
\hline Zscore(BTD2) & 268 & -3.55295 & .69790 \\
\hline Zscore(BTD3) & 268 & -2.93830 & .72859 \\
\hline Zscore(BTD4) & 268 & -1.93123 & 1.07790 \\
\hline Zscore(BTD5) & 268 & -2.15900 & .96863 \\
\hline Zscore(PRC1) & 268 & -.69715 & 2.55219 \\
\hline Zscore(PRC2) & 268 & -.89070 & 2.23989 \\
\hline Zscore(PRC3) & 268 & -.42401 & 3.94657 \\
\hline Zscore(PRC4) & 268 & -.76568 & 2.64018 \\
\hline Zscore(PRC5) & 268 & -.81511 & 2.72253 \\
\hline Zscore(PRC6) & 268 & -.85587 & 1.84264 \\
\hline Zscore(PRC7) & 268 & -1.43969 & 1.40257 \\
\hline Zscore(PRC8) & 268 & -.89318 & 2.76135 \\
\hline $\begin{array}{l}\text { Valid N } \\
\text { (listwise) }\end{array}$ & 268 & & \\
\hline
\end{tabular}

\subsubsection{Normality}

After having satisfied the two preliminary conditions of non-missing data and no outliers in the data set, the important one is normality. The table below displays skewness and kurtosis statistics of the current data. It is evident that none of the items have the exceeding values for kurtosis and skewness and no issue, such as non-normality. We can safely proceed to further analysis. 
Alharbi Nesreen Nasser A., Yanhui Li

Effects of Privacy Policy and Government Regulation on Trust of Consumers in Saudi Arabia: An Empirical Study

Table 7: The Skewness and Kurtosis values of normality

\begin{tabular}{lcllll} 
& \multirow{2}{*}{ Statistic } & S. & S. & K. & K. \\
& & Statistic & Std. Error & Statistic & Std. Error \\
\hline GOVERNMENT REGULATION & 268 & -1.086 & .149 & .963 & .297 \\
PRIVACY POLICY & 268 & -.779 & .149 & .253 & .297 \\
BENEFIT TO DISCLOSE & 268 & -.856 & .149 & .407 & .297 \\
WILLINGNESS TO PROVIDE268 & -1.227 & .149 & 1.232 & .297 \\
PERSONAL INFORMATION & & & & & \\
TRUST & 268 & -1.396 & .149 & 1.912 & .297 \\
PRIVACY RISK CONCERN & 268 & 1.131 & .149 & 2.737 & .297 \\
Valid N (listwise) & 268 & & & &
\end{tabular}

\subsubsection{Linearity}

According to Hair et al. (2006), the linearity in the variables is assumed to be existent. If it does not exist, then there is the potential of singularity and multicollinearity. The potentially collinear variables have a correlation coefficient of 0.90 or above (Hair et al. 2010). The correlation table shows the values of the correlation coefficient. We found no such correlation having a higher correlation coefficient than 0.90 . Hence, there is no issue of multicollinearity.

Table 8: Correlation matrix of variables in Model 1

\begin{tabular}{|c|c|c|c|c|c|c|}
\hline & & & TRUST & $\begin{array}{c}\text { PRIVACY RISK } \\
\text { CONCERN }\end{array}$ & $\begin{array}{l}\text { PRIVACY } \\
\text { POLICY }\end{array}$ & $\begin{array}{l}\text { GOVERNMENT } \\
\text { REGULATION }\end{array}$ \\
\hline \multicolumn{3}{|c|}{ Pearson Correlation } & 1 & $-.594^{* *}$ & $.597^{* *}$ & $.840^{* *}$ \\
\hline \multicolumn{3}{|c|}{ TRUST Sig. (2-tailed) } & & .000 & .000 & .000 \\
\hline \multicolumn{3}{|l|}{$\mathrm{N}$} & 268 & 268 & 268 & 268 \\
\hline \multicolumn{3}{|c|}{ Pearson Correlation } & $-.594^{* *}$ & 1 & $-.543^{* *}$ & $-.569^{* *}$ \\
\hline PRIVACY & RISK & Sig. (2-tailed) & .000 & & .000 & .000 \\
\hline CONCERN & $\mathrm{N}$ & & 268 & 268 & 268 & 268 \\
\hline \multicolumn{3}{|c|}{ Pearson Correlation } & $.597^{* *}$ & $-.543^{* *}$ & 1 & $.592^{* *}$ \\
\hline \multicolumn{2}{|c|}{ PRIVACY POLICY } & Sig. (2-tailed) & .000 & .000 & & .000 \\
\hline \multicolumn{3}{|l|}{$\mathrm{N}$} & 268 & 268 & 268 & 268 \\
\hline \multicolumn{3}{|c|}{ Pearson Correlation } & $.840^{* *}$ & $-.569^{* *}$ & $.592^{* *}$ & 1 \\
\hline GOVERNMENT & \multicolumn{2}{|c|}{ Sig. (2-tailed) } & .000 & .000 & .000 & \\
\hline REGULATION & \multicolumn{2}{|l|}{$\mathrm{N}$} & 268 & 268 & 268 & 268 \\
\hline
\end{tabular}

\subsection{Research Hypotheses Testing}

In this section, we test the study hypotheses. The table below lists hypotheses found in the study. There are two models in the survey, each comprising of five hypotheses. To distinguish two models, the hypotheses of model1 are denoted by (a).

Table 9: Hypotheses of the Study (Model 1)

H1a: Privacy policy has a positive impact on trust.

$\mathrm{H} 2 \mathrm{a}$ : Privacy policy has a negative impact on privacy risk concerns. H3a: Government regulation has a positive impact on trust.

H4a: Government regulation has a negative impact on privacy risk concerns.

$\mathrm{H} 5 \mathrm{a}$ : Privacy risk concern have a negative impact on trust 
Alharbi Nesreen Nasser A., Yanhui Li

Effects of Privacy Policy and Government Regulation on Trust of Consumers in Saudi Arabia: An Empirical Study

The hypotheses mentioned above were tested using multiple regression analysis. The ten direct relationships are examined by using regression analysis.

\begin{tabular}{cc}
\hline & Table 10: Regression 1 \\
Dependent Variable & Independent variables \\
\hline \multirow{2}{*}{ Trust } & PRIVACY POLICY \\
& GOVERNMENT REGULATION \\
& PRIVACY RISK CONCERN \\
\hline
\end{tabular}

Table 11: Regression (1) in the model (1)

\begin{tabular}{ccccccr}
\hline & & & \multicolumn{2}{c}{$\begin{array}{c}\text { Unstandardized } \\
\text { Coefficients }\end{array}$} & \multicolumn{2}{c}{$\begin{array}{c}\text { Standardized } \\
\text { Coefficients }\end{array}$} \\
& & \multicolumn{3}{c}{ Std. } \\
Hypotheses & Independent Variables & B & Error & Beta & t & Sig. \\
\hline H1 & PRIVACY POLICY & .114 & .043 & .111 & 2.672 .008 \\
H3 & GOVERNMENT & .680 & .041 & .696 & 16.396 .000 \\
H5 & REGULATION & PRIVACY RISK & -.161 & .048 & -.138 & -3.393 .001 \\
& CONCERN & & & & &
\end{tabular}

a. Dependent Variable: TRUST

Table 12: Regression 2

Dependent Variable Independent variables

Privacy Risk Concern

PRIVACY POLICY

GOVERNMENT REGULATION 
Alharbi Nesreen Nasser A., Yanhui Li

Effects of Privacy Policy and Government Regulation on Trust of Consumers in Saudi Arabia: An Empirical Study

Table 13: Regression (2) in model (1)

\begin{tabular}{ccccccr}
\hline & & \multicolumn{3}{c}{$\begin{array}{c}\text { Unstandardized } \\
\text { Coefficients }\end{array}$} & $\begin{array}{c}\text { Standardized } \\
\text { Coefficients }\end{array}$ & \\
Hypotheses & Independent Variables & B & Std. Error & Beta & t & Sig. \\
\hline H2 & PRIVACY POLICY & -.280 & .053 & -.317 & -5.326 .000 \\
H4 & GOVERNMENT & -.320 & .050 & -.382 & -6.408 .000 \\
& REGULATION & & & & & \\
& & & & & & \\
\end{tabular}

a. Dependent Variable: Privacy Risk Concern

Table 14: Summary of Hypotheses (Model 1)

\begin{tabular}{|c|c|c|}
\hline Hypotheses of the Study (Model 1) & P-value & Results \\
\hline H1a: Privacy policy has a positive impact on trust. & .008 & Supported \\
\hline H2a: Privacy policy has a negative impact on privacy risk concerns. & .000 & Supported \\
\hline H3a: Government regulation has a positive impact on trust. & .000 & Supported \\
\hline $\begin{array}{l}\text { H4a: Government regulation has a negative impact on privacy risk } \\
\text { concerns. }\end{array}$ & .000 & Supported \\
\hline H5a: Privacy risk concern have a negative impact on trust & .001 & Supported \\
\hline \multicolumn{3}{|c|}{$\begin{array}{l}\text { The above table of summary of hypotheses shows that all hypotheses presented in model } \\
\text { are supported as their } p \text {-values are less than } 0.05 \text {. We found the significant positive impact } \\
\text { the privacy policy on trust, the significant negative impact of the privacy policy on privacy ris } \\
\text { concern, the significant positive impact of government regulation on trust, the significan } \\
\text { negative impact of government regulation on privacy risk concern and significant negative } \\
\text { impact of privacy risk concern on trust. }\end{array}$} \\
\hline
\end{tabular}

\section{Discussion of Key Results}

\section{H1a: Privacy policy has a positive impact on trust.}

The result of the $\mathrm{H} 1$ a suggested that privacy policy has a positive impact on trust $(\beta=0.111$, $\mathrm{P}<0.05$ ). The website privacy policy is provided to the user to illustrate the purpose of data collection and its usage. It is evident that users do not consider its importance and ignore it (Canada, 2013). This can be due to different reasons; the major being the extensive content users are unable to read (Emakova et al., 2014), too much information that does not attract the user (Schaub, Breaux, and Sadeh, 2014). The respondents suggested they are not able to read the privacy policy due to its complexity and, most importantly, protecting the organization prominently (Williams, Agarwal and Wigand, 2015). Privacy policies a im to raise the aw areness to inform the users on how the organizations are collecting and using the data for their purpose. The research analyzed the distinction among the illustration of experts and the users (Reidenberg et al., 2014). The study aimed to investigate the user's capability to undertake the privacy policy so that they would be able to decide about the confidential information access. The findings of the study suggest that there are different issues in the illustration of the privacy policies, especially in the language, and pertaining to the sharing of the information. Electronic government services are based upon the customers' trust that can rely 


\section{Alharbi Nesreen Nasser A., Yanhui Li \\ Effects of Privacy Policy and Government Regulation on Trust of Consumers in Saudi Arabia: An Empirical Study}

upon the privacy (which is a trust). The study analyzed the relationship between the buyer and seller.

Buyer's trust is one of the main features applied in the development of the Privacy - Trust Behavioral Intention Model (Liu, Marchewka, Lu and Yu, 2004a). This model illustrates the privacy's impact on trust, and the impact upon consumers' behavior intention regarding the internet-based transactions. It is evident that a clear and transparent privacy policy helps organizations to maintain relations with the consumers (Schoenbachler and Gordon, 2002). If a suggested privacy policy is clear, then it will engage users and initiate the development of their trust and confidence adequately. Based on a similar concept, researchers are focusing on the significant relations between the privacy policy and trust. The current study's findings are in line with previous work.

\section{H2a: Privacy policy has a negative impact on privacy risk concerns.}

The result of the $\mathrm{H} 2 \mathrm{a}$ suggested that privacy policy has a negative impact on privacy risk concern $(\beta=-0.317, P<0.05)$. There are different concerns related to privacy policy and risk. Internet-based privacy is considered as the freedom to use the website and its information adequately (Dhillon and Moores, 2001). From the consumers' or users' perspective, if they cannot maintain control over the information websites collects, they are bound to show high privacy concerns. Different researchers are focusing on different perspectives concerning privacy and its results; how ever, some researchers developed the link between experience and privacy concerns. Privacy concerns are the main problem for internet users (Dinev and Hart et al., 2006; Malhotra et al., 2004). Trust is the main feature in the technologically advanced environment (Fukuyama, 1996).

In the case of public surveys, citizens are under the threat that others can access their personal information, thus breaching the privacy policy (Equifax, 1996; Harris and Westin, 1998; Westin,1997). It is evident that privacy issues reflect on customers negatively, as in the case of intentional disclosure of personal information to business (Culnan and Armstrong, 1999; Dinev and Hart, 2006; Malhotra et al., 2004; Stewart and Segars, 2002). Internet-related privacy issues manifest in customers not being willing to disclose their information freely on the internet (Dinev and Hart, 2006). Another study suggested that privacy issues impact the will of the customer, and they are not willing to provide information to the electronic vendors (Premazzi et al., 2010).

Currently, researchers are testing divergent concepts focusing on the consumer's motivation to disclose their personal information. Previous studies suggested that consumers consider the risk and benefit while sharing the information on social networks (Gross and Acquisti, 2005; Chellappa and Sin, 2005), during online transaction (Hui et al., 2006) and mobile transactions as well (Keith et al., 2012) prior deciding to disclose their personal information. In the past, researchers conducted analyses to assess the relationship between the privacy policy and privacy risk. As for the current study, the investigation is made in relation to the adoption of e-government, where privacy policy and its associated risk is the major concern for the users.

\section{H3a: Government regulation has a positive impact on trust.}

The result of the $\mathrm{H} 3$ a suggested that government regulation has a positive impact on trust ( $\beta$ $=0.696, \mathrm{P}<0.05)$. Government rules and regulations exist to protect personal information at any cost (Xu et al., 2010). It is mandatory to comply with government regulations concerning the disclosure of personal information and sharing or using data. The main objective is to trigger the consumers' willingness to share the information. Law enforcement shall increase users' trust and enhance reliability with regards to the application of the governmental laws concerning data protection and the privacy policy. 


\section{Alharbi Nesreen Nasser A., Yanhui Li \\ Effects of Privacy Policy and Government Regulation on Trust of Consumers in Saudi Arabia: An Empirical Study}

The current research work maintains the government laws shall increase consumers' trust. The practical application of government laws about the privacy protection of information will increase the users' trust and motivate them to use electronic government services further. The research emphasized the importance of trust, giving priority to the social relation concerning its development rather than relying upon the personal psychological condition (Lewis and Weigert in Tan and Sutherland, 2004). In the case of institutions, trust is associated with the institutional atmosphere. The structure, laws, and rules all make up the system on which the trust in the organizational environment can be built (Zucker, 1986; Hussein et al., 2009). Institutional trust is conceptualized as the intention to adopt the uncertainty of the institutional atmosphere like structure, laws, system, and other services (Colquitt et al., 2007). As far as the e-government is concerned, institutional trust is assumed to adopt the uncertain environment of the organization towards electronic government services and other online features.

\section{H4a: Government regulation has a negative impact on privacy risk concerns.}

The result of the $\mathrm{H} 4 \mathrm{a}$ suggested that government regulation has a negative impact on privacy risk concern $(\beta=-0.382, P<0.05)$. After 1980 , different countries used and implemented privacy protection laws in order to protect personal information from possible breach and unlawful usage. In the developed countries, sanctions were executed with the objective of developing users' confidence and trust to get the information and conduct their business adequately and freely. OECD produced guidelines enabling the government to harmonize the national laws with the emphasis on human rights (OECD 1980). Government laws allow the individual to give up personal control rather than relying upon the regulations to become active in order to protect the personal information. The study suggests that the legal system is a powerful feature for the implementation of the control, thus allowing law enforcement to penalize those committing cyber crimes and breaching the information protocol (Spiro and Houghtelig, 1981). The law states that there are different kinds of information companies and third parties that can collect the consumer's information, but breach and misuse will be highly reprehensible (Swire, 1997). There are different governmental agencies existing in order to provide protection and support to those who were victims of privacy breaches pertaining to their personal information (Culnan and Bies, 2003).

The existence of government laws increases individuals' trust and confidence that their information should be protected under the law. Therefore, rules and regulations have reduced fear and privacy policy risks. It is evident that the quality of the laws will be useful in motivating individuals to provide their personal information without fear that the data will be misused (Lwin, Wirtz, and Williams, 2007). The implementation of government laws concerning information protection is highly commendable. It is evident that the use of advanced technology is prominent, but there are still remaining problems in order to meet the recommended regulations (Raab and Szekely, 2017). A survey on privacy suggests that people do not confide in government rules and regulations about privacy; therefore, only a few people share their personal information with the government (The Surveillance Project, 2008). Government privacy policies and laws are the essential features for the online privacy research context (Ginosar and Ariel 2017).

\section{H5a: Privacy risk concerns have a negative impact on trust.}

The result of the $\mathrm{H} 5 \mathrm{a}$ suggested that privacy risk concern has a negative impact on trust ( $\beta=$ - 0.138, $\mathrm{P}<0.05)$. In the past researches, ICT was engaged in information sharing with government regulations. Advancement of technology has complicated the use and impacted the effectiveness of ICT (Acquilina, 2010). The government's priority is to protect the citizens' personal information by fostering their trust (Alawneh, Al Refai, and Batiha, 2013). Issues associated with the citizens' privacy in the technological environment make up the most significant challenge that, once eradicated, will make electronic government successful and helpful to the people (Belanger and Hiller, 2006). Privacy trust is assumed to be a belief of the 


\section{Alharbi Nesreen Nasser A., Yanhui Li \\ Effects of Privacy Policy and Government Regulation on Trust of Consumers in Saudi Arabia: An Empirical Study}

individual that provided information will be safe, and there will be no breach (McLeod and Pippin, 2009). The study identified a few more issues concerning privacy (Wright et al., 2009). The findings of the impact government laws concerning privacy are having on people, from peoples' perspective, is negative because they do not believe in the laws. It is evident that the internet lacks the information and resource to analyze data security and trust the laws protecting this information (Acquisti et al., 2015). In view of the government laws of privacy, it urges the organization to maintain the trust of the individuals and protect the information that is provided by the users in order to meet the consumer satisfaction level (Ginosar and Ariel, 2017.

\section{Conclusion and Contributions}

\subsection{Conclusion}

The study found that: First, the privacy policy has a positive impact on trust. A clear and transparent privacy policy helps organizations to establish good relationships with consumers. The government should first define the privacy policy before fully developing the trust and confidence of users. Second, the privacy policy has a negative impact on privacy risk concerns, and a strong and pow erful privacy policy will significantly improve users' conservative attitudes about information sharing and privacy disclosure risks. Third, government regulation has a positive impact on trust. Government regulations such as disclosure, sharing, and use of personal information must be enforced to increase the willingness to use users' informa tion, thereby enhancing users' trust in the relevant privacy policy protection laws. Fourth, government regulation has a negative impact on privacy risk concerns. Clear and effective laws and regulations reduce users' fear of privacy policy; that is, the quality of the law will effectively motivate users to provide personal information. Fifth, privacy risk concerns have a negative impact on trust. When the perceived risk of users after sharing personal information is great, the degree of trust will be reduced accordingly, which will affect the degree of personal information disclosure.

\subsection{Study Implications and Contributions}

The research aimed to analyze the influence of privacy policy and government regulation on privacy risk concerns and trust. In other words, this paper attempted to highlight the importance of privacy policy and government regulations, which are two important aspects related to user's privacy rights. The findings of the research imply that there is a high level of concern among the citizens linked to their privacy risk, indicating people do not trust egovernment sufficiently. This is accounted for by the fact that there is a lack of privacy policy. Taking into consideration weak spots related to e-government policies, this study has a number of implications. Firstly, there is a strong need to adopt cybersecurity plan. Besides that, consumers' trust related to privacy policy should be increased. This can be done by improving the standards for a privacy policy. The unique contribution of the following study model can be seen in terms of the comparison of different theoretical models.

\section{References}

- Alawneh A, Al-Refai H, Batiha K. Measuring user satisfaction from e-Government services: Lessons from Jordan. Government Information Quarterly, 2013, 30(3): 277-288 Crossref

- Aquilina K. Public security versus privacy in technology law : A balancing act? Computer Law \& Security Review, 2010, 26(2): 130-143 Crossref

- Belanger F., Hiller J S., Smith W J. Trustworthiness in electronic commerce: the role of privacy, security, and site attributes. Journal of Strategic Information Systems, 2002, 11(34):245-270 Crossref

- Colquitt J A, Scott B A, LePine J A. Trust, trustworthiness, and trust propensity: A meta analytic test of their unique relationships with risk taking and job performance. Journal of applied psychology, 2007, 92(4): 909 Crossref 
- Culnan M J, Armstrong P K. Information Privacy Concerns, Procedural Fairness, and Impersonal Trust: An Empirical Investigation. Organization Science, 1999, 10(1):104-115. Crossref

- Culnan M J, Bies R J. Consumer Privacy: Balancing Economic and Justice Considerations. Journal of Social Issues, 2010, 59(2):323-342 Crossref

- Culnan M J. "How Did They Get My Name?": An Exploratory Investigation of Consumer Attitudes Toward Secondary Information Use. Mis Quarterly, 1993, 17(3):341-363. Crossref

- Dhillon G S, Moores T T. Internet Privacy: Interpreting Key Issues. Information Resources Management Journal, 2001, 14(4):33-37 Crossref

- Dinev T., Hart P. Internet privacy concerns and their antecedents - measurement validity and a regression model. Behaviour \& Information Technology, 2004, 23(6):413-4227 Crossref

- Equifax, Inc, Louis Harris and Associates. Equifax-Harris consumer privacy survey. Equifax, 1996.

- Ermakova T, Baumann A, Fabian B, et al. Privacy Policies and Users' Trust: Does Readability Matter?//Twentieth Americas conference on information systems, 2014

- Fukuyama F. Trust Still Counts in a Virtual World" This disembodied organization exists without institutions, without loyalties, without face-to-face interaction.". Forbes, 1996, 158: 33-35

- Hair, J. E., Anderson, R. E., Tatham, R. L., and Black, W. C.. Multivariate data analysis. (5th ed.). Upper Saddle River, NJ: Prentice-Hall.

- Hair, J.F. Jr., Black, W.C., Babin, B. J. and Anderson, R.E. Multivariate data analysis. 7th ed. New Jersey: Pearson Prentice Hall, 2010.

- Hair, J.F., Black, W.C., Babin, B.J., Anderson, R.E. and Tatham, R.L., Multivariate data analysis : Pearson Prentice Hall. Upper Saddle River, NJ, 2006

- Harris L, Westin A F. E-commerce and privacy: What net users want. Privacy and American Business, Hackensack, NJ, 1998.

- Hui K L, Goh C Y, Goh C Y. Online information disclosure: Motivators and measurements. 2006. Hui K L, Tan B C Y, Goh C Y. Online information disclosure: Motivators and measurements. ACMTransactions on Internet Technology (TOIT), 2006, 6(4): 415-441. Crossref

- Hussein R, Mohamed N, Ahlan A R, et al. Modeling G2C adoption in developing country: a case study of Malaysia. AMCIS 2009 Proceedings, 2009: 408

- Information Systems Research, 2002, 13(1):36-49 Crossref

- Junglas I A., Johnson N A., Spitzmüller, Christiane. Personality traits and concern for privacy: an empirical study in the context of location-based services. European Journal of Information Systems, 2008, 17(4):387-402 Crossref

- Keith M J, Thompson S C, Hale J, et al. Information disclosure on mobile devices: Reexamining privacy calculus with actual user behavior. International Journal of Humancomputer Studies, 2013, 71(12):1163-1173 Crossref

- Liu C, Marchewka JT, Lu J, et al. Beyond concern-a privacy-trust-behavioral intention model of electronic commerce. Information \& Management, 2005, 42(2):289-304 Crossref

- Malhotra N K , Agarwal K J . Internet Users' Information Privacy Concerns (IUIPC): The Construct, the Scale, and a Causal Model. Information Systems Research, 2004, 15(4):336355. Crossref

- Mcknight D H, Chervany N L. What Trust Means in E-Commerce Customer Relationships: An Interdisciplinary Conceptual Typology. International Journal of Electronic Commerce, 2001, 6(2):35-59. Crossref

- McLeod A J, Pippin S E. Security and privacy trust in e-government: Understanding system and relationship trust antecedents//2009 42nd Hawaii International Conference on System Sciences. IEEE, 2009: 1-10

- Milne G R, Culnan M J. Strategies for reducing online privacy risks: Why consumers read (or don't read) online privacy notices. Journal of Interactive Marketing, 2010, 18(3). Crossref 
- Reidenberg J R, Breaux T, Cranor L F, et al. Disagreeable privacy policies: Mismatches between meaning and users' understanding. Berkeley Tech. LJ, 2015, 30: 39. Crossref

- Schaub F, Breaux T D, Sadeh N. Crowdsourcing the extraction of data practices from privacy policies//Second AAAI conference on human computation and crowdsourcing. 2014

- Segars S A H. An empirical examination of the concern for information privacy instrument.

- Smith H J., Burke M S J . Information privacy: Measuring individuals concerns about organizational practices. MIS Quarterly, 1996, 20(2):167-196. Crossref

- Spiro G W, Houghteling J L. The dynamics of law. 1992.

- Swire PP Markets, self-regulation, and government enforcement in the protection of personal information. Daley WM, Irving L, eds. Privacy and Self-Regulation in the Information Age (Department of Commerce, Washington, DC), 3-

- Warren S D, Brandeis L D. The right to privacy. Harvard Law Review, 1985, 4(5):193-220. Crossref

- Westin A F. Commerce, communication, and privacy online. Center for Social and Legal Research, NJ, 1997

- Williams T L, Agarwal N, Wigand R T. Protecting private information: Current attitudes concerning privacy policies. 2015

- Xu H, Teo H H, Tan B CY, et al. The role of push-pull technology in privacy calculus: the case of location-based services. Journal of management information systems, 2009, 26(3): 135174. Crossref

- Zucker L G. Production of trust: Institutional sources of economic structure, 1840-1920. Research in Organizational Behavior, 1986, 8(1): 53-111. 